\title{
Victor Semeonovich Gurfinkel (April 2, 1922-January 14, 2020)
}

\author{
Yury Invanenko ${ }^{1}$ - Alain Berthoz ${ }^{2} \cdot$ Paul Cordo $^{3,4}$
}

Published online: 31 March 2020

๑) Springer-Verlag GmbH Germany, part of Springer Nature 2020

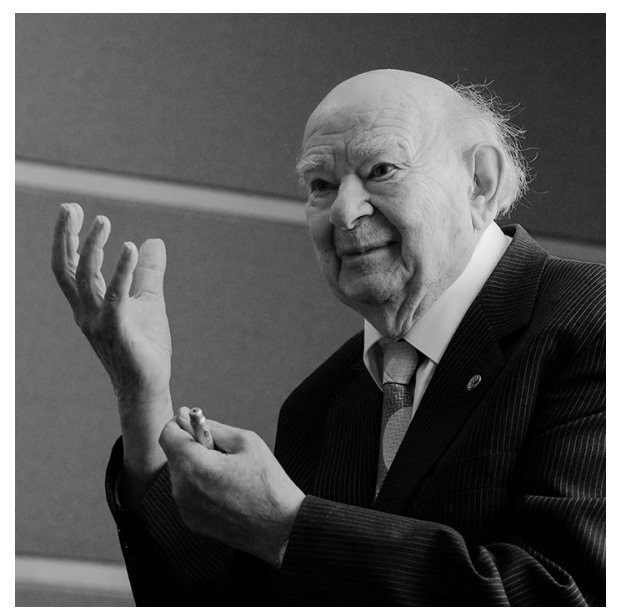

Victor S. Gurfinkel was born on April 2, 1922, in the small town of Okny, Ukraine. His father was a doctor, and Victor was the youngest of four siblings. In 1939, after graduating from high school, he enrolled into Medical College in Odessa, but in 1941, after the start of the WWII, the school was evacuated, and he continued his studies in Kirgizia, graduating in 1944. After finishing medical school, Victor immediately joined the army on the Northern Front (Karelia), but soon was transferred to the Belarussian Front, in charge of blood transfusion services for the 19th Army. He ended the war in Poland, in charge of the Soviet Army lab that worked with amputee soldiers to provide them with artificial limbs. After leaving the army, Victor continued his prosthetic development work at the Institute of Prosthetic

Paul Cordo

pcordo@amesdevices.com

1 IRCCS Fondazione Santa Lucia, Rome, Italy

2 Collège de France, Paris, France

3 AMES Technology, Inc., 2675 SW Brae Mar Court, Portland, OR 97201, USA

4 Oregon Health and Sciences University, Portland, OR, USA

Appliances in Moscow, where he started his research career working with Professor Nicolai Bernstein. In 1950, he completed his $\mathrm{PhD}$, and in 1961, he received a D.Sc in biophysics. For his contribution to research in prosthetic development he was awarded the State Prize in 1970.

Victor Gurfinkel's scientific carrier spanned more than 70 years. Each era of Victor's research career brought forth new and insightful knowledge that influenced thinking in his field. He was inspired by the thoughts of N. Bernstein, which he enriched and, thereby, contributed to a revolution in Western physiology that had been dominated by reflexology. Much of his research involved the study of the internal representation of the body and external space in the human brain, to understand how the brain forms the models on the basis of which motor behavior is realized. His concept of the role of the "body schema" in generating the physical configurations of the body for action, in an anticipatory process, was a key concept not only for modern physiology but also for a completely novel approach to many pathologies. His main scientific interest was the control of posture and movement in humans. He was a pioneer in the use of stabilography for the study of human upright posture. He had a particular interest in the normal regulation of and disturbances to muscle tone and how these disturbances affect movement performance. He was also interested in the biophysical mechanisms of skeletal muscle contraction. His studies of postural regulation led him to conclude that the motor system is not reduced to a set of simple postural reflexes. He was also involved in the development of the principles of adaptive control of robots and manipulators, the development of modular torque sensors and other devices for processing this sensor information in robots, in particular, for an ambulating six-legged walking device. He contributed to several space flights in the MIR station with the French CNES. In 1981-1983, Victor helped guide a large research project ("Pose"), performed aboard the Salyut-7 orbital station to investigate the physiological mechanisms of human adaptation to microgravity and spatial orientation during spaceflight. He and his wife Irene moved to Portland, Oregon in the US where he continued to do research and train students during the early 1990s. 
Over his career, he was the author of 3 monographs and more than 300 scientific publications in the field of physiology, biophysics, and robotics.

The long and fruitful career of Victor Gurfinkel is continued in the works of his students and followers-representatives of the scientific school he created. Many of them became leaders in their own fields and founders in their own scientific areas, but Victor Gurfinkel's concepts continue to serve as a source of fruitful ideas for them. He was a deep thinker and produced pioneering ideas until his last days. He was a master and friend of many of us. We will miss his inspiration and wisdom. We can commemorate his memory in the only way he would approve-by continuing his work.
To post photos, anecdotes, and personal experiences for all to see, please forward to the following link: http://iitp.ru/ en/about/gurfinkel.

Publisher's Note Springer Nature remains neutral with regard to jurisdictional claims in published maps and institutional affiliations. 